I can hardly imagine how he can regard such fear as inexplicable (Webster: "incapable of being explained or interpreted, mysterious"; Shorter OED: "that cannot be explained, unintelligible, unaccountable"). Even if therapeutically effective, is it really so difficult to think of any possible reason why a patient might grow fearful of receiving ECT without anaesthetic ?

Michael A Simpson

London NW3

\section{Oesophageal cancer}

SIR,-_Your leading article (17 July, p 135) on oesophageal cancer is welcome in drawing attention to the importance of dysphagia in this disease. As you so rightly state, it is a symptom requiring urgent investigation.

However, to suggest that radiotherapy is the preferred treatment for middle third lesions is incorrect. From the surgical point of view there is no difference in treating middle or lower third lesions. The disadvantage with radiotherapy is that symptomatic relief is given, but the patient all too frequently returns with dysphagia due to tumour at the original site. Successful treatment at this stage is impossible. Surgery and further radiotherapy are not feasible. As a result a tube is inserted to enable the patient to swallow saliva and fluid nutrition. This is poor palliation and does not improve the quality of life. In contrast, with oesophagectomy it is unusual for the patient to develop recurrent dysphagia, and a normal diet may be taken, one of the few pleasures many elderly people have left. Although the five-year survival rate with surgery is not good, the quality of life, a matter stressed in your leader, in the majority of patients is good.

Undoubtedly radiotherapy has a place in the treatment of oesophageal cancer, though at present it is not the preferred treatment of middle third lesions. The results in oesophageal cancer can be improved, and the first step is to investigate urgently all patients with dysphagia.

Southampton Western Hospital, Southampton

\section{Preventive nutrition}

SIR, - It is encouraging to find that preventive nutrition has found a place among your leading articles (17 July, 134), but I believe there is a better way of putting this aspect of nutrition on to a sound footing than by upgrading dietitians, and which would encourage students and young doctors to take a real interest in the subject and would also be of value to the dietitians. This is to introduce consultant nutritionists into the community health side of the NHS at district level, so that they can work both with the population and with other colleagues. ${ }^{1}$ At present they tend to be rather remote in academic and research posts.

A major justification of this proposal is the challenge of the great increase in deaths from coronary artery disease in the UK from approximately 1000 per year in 1921 to about 96000 per year in 1961.2 The existing emphasis on lipid biochemistry needs to be balanced by field studies of the diet of individuals, especially the effect of the large degree of processing and use of preservatives and additives. ${ }^{3}$ There are also regional differences in the death rate of this disease which are wide open to study. There was an SMR between 1954 and 1958 in the UK among women of 145 per 1000 in such places as Aberdeenshire, East Lothian, and Wigtownshire, but only 70 per 1000 among women in East Cambridgeshire and Rutland and from Montgomeryshire to the north-west coast of Wales around Caernarvon. Differences of these magnitudes do not happen by chance. ${ }^{3}$ Nutritionists working in these areas as part of the local staff of the NHS should be able to find answers to some of these differences which would greatly assist in prevention.

There are other field nutritional problems, for example, among the aged, the neurotic, the mentally subnormal, the sociologically abnormal; rickets among all races; and the growth and nutrition of all normal young people. ${ }^{4}$ In all these a consultant nutritionist at local NHS level, with the help of dietitians, would find full scope for his expertise. Together they would be far more effective than either alone.

\section{Chipping Sodbury,
Bristol}

R Y TAYLOR

\section{Report of the Agricultural Research Councill/Medical Research Council Committee. London, HMSO, 1974 . Witts, L J, Medical Surveys and Clinical \\ London, Oxford University Press, 1963.
Agricultural Research Council/Medical Research Agricultural Research Council Medical Research
Council Committee, National Atlas of Disease Mortality in the United Kingdom. London, Nelson, \\ - Taylor, R Y, Public Health, 1966, 80, 146.}

The placenta as an immunological barrier

SIR,-YYour leading article (24 April, p 975) summarises the expanding knowledge concerning the hormonal functions of the placenta, but we would like to comment on a further related function which may prove to be of some importance.

It is now generally accepted that the fetus is an allograft but the mechanism which prevents its rejection by the mother is uncertain. The fetus is separated from the mother by the placenta, and the mechanical barrier between the two circulations clearly plays some part in protecting the fetal allograft. We have previously $^{1}$ suggested that the protection of the fetal allograft cannot be solely ascribed to the mechanical barrier afforded by the placenta, as the placenta is permeable to a wide range of substances, including certain antibodies. It is likely, therefore, that there is some form of immunological tolerance between mother and fetus.

Maternal lymphocyte function is depressed in pregnancy as measured by the reduction in PHA-induced transformation, ${ }^{12}$ and this could form part of the tolerance mechanism. Several factors have now been isolated which act as lymphocyte depressants and these include chorionic gonadotrophin, $x$-fetoprotein, and prolactin. We have recently repeated and confirmed the work of Riggio $e t a l^{3}$ and have extracted a glycoprotein from the placenta which depresses PHA-induced lymphocyte transformation. It is more powerful than the other lymphocyte inhibitors and at a concentration of $5 \mathrm{mg} / \mathrm{ml}$ PHA-induced lymphocyte transformation is almost completely blocked. Sephadex gel filtration separated the extract into four fractions, and the most active of these was the fraction of molecular weight 800020000 . The size of the molecule indicates that it is distinct from chorionic gonadotrophin and $\alpha$-fetoprotein. Further chemical characterisation studies are in progress.

The placenta therefore secretes at least two factors which depress maternal lymphocytes and may induce tolerance to fetal tissues, and so plays a part in protecting the fetal allograft. The placenta is clearly a much more complicated organ than was realised a few years ago. It has long been appreciated that it acts as a purely mechanical barrier between mother and fetus, but the evidence is now growing that it also acts as a much more sophisticated immunological barrier between mother and fetus. It is likely that the placenta will eventually be shown to play a crucial role in protecting the fetal allograft from rejection by the maternal immune system.

Ronald FinN J C Davis

C A St Hill L J HIPKIN

Royal Southern Hospital, Liverpool MARJORIE HARVEY

and Department of Endocrine Pathology,

' Finn, R, et al, British Medical fournal, 1972, 3, 160.

2 Purtilo, D T, et al, Lancet, 1972, 1, 769.

\section{Cold extremities and beta-blockers}

SIR,-The recent article of Dr A J Marshall and others (19 June, p 1498) reporting the increased incidence of cold hands and feet due to beta-blockade confirms other reports in the literature. In addition the authors suggest that propranolol is more frequently implicated than other beta-blockers as also did Zacharias. ${ }^{1}$ However, it would appear that none of the patients of Marshall et al had the symptom prior to treatment, which seems a little surprising when considering the average age and state of the vascular tree of most patients on beta-blocking drugs.

In Dundee we have been conducting a survey of patients in the area who have had this form of therapy. The majority have a diagnosis of hypertension or angina and 171 have been seen so far. Of these, 54 have been on a combination of beta-blockers, but 19 have been on practolol alone, 42 on propranolol alone, and 56 on oxprenolol alone.

Considering those 117 patients who have been on one beta-blocker only, 22 admitted to cold extremities before treatment and a further 18 have developed symptoms since starting treatment. Five of those already having symptoms stated that the drug made their symptoms worse-that is, 23 patients have been affected. Both the normal group and the group developing symptoms have been on therapy for a comparable period of time. Before beta-blocker treatment significantly more females, 18 of $63(29 \%)$ as compared to 4 of $54(7 \%)$ males, complained of cold extremities $(\mathrm{P}<0.05)$. After treatment, although a higher incidence was found in females than males, this difference was not significant. The total number affected after treatment who were over 60 years of age was 17 of 60 compared to 6 of 57 in the under- 60 s, a difference significant at the 5\% level.

The proportion of patients who were affected by the beta-blocker were as follows: 9 of $42(21 \%)$ on propranolol, 2 of $19(11 \%)$ on practolol, and 12 of $56(21 \%)$ on oxprenolol. So far there is no evidence from our survey 
which would implicate propranolol to a greater extent than oxprenolol as a cause of cold extremities. However, we agree that prospective studies could provide a definitive picture and would be particularly useful in establishing the clinical significance of this side effect.

D TRASH

M GRUNDMAN

JANICE CARGILL

L CHRISTOPHER

Ninewells Hospital,

Dundee Zacharias, F J, Postgraduate Medical fournal, 1971,
47, Suppl, 75.

\section{Doctors, contraception, and sterilisation}

SIR,-Mr A R Hill's letter (31 July, p 303) concerning the vocation of doctors seems to introduce a fundamental issue regarding their function in modern-day practice. I had always understood that the purpose of the family physician is to offer total patient care. Naturally this includes the prevention and treatment of disease and injury, but surely it includes much more. The right to avoid an unwanted pregnancy must surely be available to any woman or couple, and I cannot believe that any general practitioner would abrogate this responsibility (other than on genuine religious grounds) to any other member of the community such as a chemist or nurse. The side effects of the oral contraceptives are many and may be serious, and the community doctor is in an ideal position to be consulted should untoward reactions occur. Even where religious beliefs preclude prescription or advice on contraception, usually the caring general practitioner is able to make alternative arrangements with another doctor or a family planning clinic.

With reference to the second part of the letter, vasectomy is a quick, efficient procedure to render the male sterile. It is a very satisfactory method of absolute contraception in those cases where the family is complete. If in Dr Hill's experience the operation seems to be mutilating, then I fear that the surgeons he has encountered are not of a high standard.

Please do not let us remember only the sick and infirm. There are also the unlucky, the unfortunate, and the unhappy. It is often these latter groups that medicine can help most.

P W LAMBDEN

Bromley

\section{Cardiac failure}

SIR,-In the paper on cardiac failure by $\mathrm{Dr}$ John Hamer (24 July, p 220) I missed a reference to the increasingly widespread use of vasodilators such as nitroglycerin, isosorbide dinitrate, and nitroprusside in the management of this condition, either acute or chronic.

Isosorbide dinitrate is given preference for long-term therapy of cardiac failure, as the other nitrite compounds either have transient effects or require continuous infusion and invasive haemodynamic monitoring. ${ }^{2}$ For the same reasons nitroglycerin ointments are recommended by some workers. ${ }^{3}$ Improvement of cardiac function following vasodilator therapy is so striking that some authors ${ }^{4}$ no longer regard digitalis as the drug of choice for heart failure-for example, after myocardial infarction. In many cardiological intensive care units nitrite therapy of this condition has, under careful monitoring of filling pressures, become a routine measure for preventing or controlling pulmonary oedema. The beneficial results obtained in this field have led to the extension of the indication for nitrite therapy to chronic forms of congestive heart failure. ${ }^{8} 9$

The main haemodynamic responses to vasodilator therapy may be summarised as follows: substantial increase in venous capacitance; diminished venous return; lowered ventricular filling pressure and wall tension; improved ventricular wall motion and ejection rate $^{10}$; lower pulmonary wedge pressure ${ }^{1011}$ and hence a reduction in myocardial preload and afterload-that is, in oxygen demands. Implicitly, normal myocardial metabolism is restored. ${ }^{12}$ As a consequence exercise tolerance and haemodynamics in patients with heart muscle failure of various origins are significantly improved by nitrite therapy 131 This class of drugs should therefore be kept in mind as a possible alternative or addition to the traditional treatment of congestive heart failure.

Clinical Research Division,

Gray, R, et al, American Heart fournal, 1975, 90, 346. Tikuli, E, et al, Circulation, 1975, 52, 477. Taylor, W R, et al, Abstractin Circulation, 1975, 51, 52 .
Forrester, I S, et al, Surgical Clinics of North America,
1975, 55, 351.

schrift, 1975 , 100, 749

Caltenbach, M W D, et al, Zeitschrift für Kardiologie. $1976,65,424$.

Bussmann, W D, Medisinische Klinik, 1975, 70, 1697. Cohn, J N, Circulation, 1973, 48, 5 .

Rudolph, W, et al, Her z, 1976, 1,

MeAnuly, J H, et al, Circulation, 1975, 51, 140.

Zelis, R, and Cross, CE, Internist, 1975, 16, 293.

Borer I S , et al, American fournal of Cardiology, 1975. 35,123

Chiche, $\mathrm{P}$, and Baligadoo, $\mathrm{S}$, Coeur et Médecine Interne, 1976, 15, 139.

\section{"Pastoral Paediatrics"}

SIR,-Dr John Apley (7 August, p 374) does not see Dr A W Franklin "as a wandering shepherd carrying a caduceus." This is no wonder since shepherds have not habitually carried one. According to the Roman poet Virgil the shepherd's staff was the pedum. The caduceus was the herald's staff, the token of a peaceful embassy. Mercury, the messenger of the gods, carried one with two serpents twined around it. Heralds have been described as sophisticated communicators, and as $\mathrm{Dr}$ Franklin is without doubt one of the latter he is entitled to carry a caduceus. In any case a casual observer would take it for the staff of Aesculapius.

Whitehead,

Carrickfergu

H G Calwell

\section{Epilepsy and the pill}

SIR,-There is evidence, reviewed by Robertson and Johnson, ${ }^{1}$ that some anticonvulsants can accelerate the breakdown of oestrogens and progestogens. There have been reports ${ }^{2}$ of pregnancies in epileptics taking oral contraceptives which have been ascribed to such interaction, with the recommendation that women taking anticonvulsants should not rely on oral contraception. The situation, however, has been analogous to a clinical trial of a new pill in which the numbers of failures are known but not the time the pill has been tested or the number of women involved. While analysing records of inadvertent pregnancies in the Royal College of General Practitioners' oral contraceptive study ${ }^{4}$ in connection with recurrent pill failures I thought the data might help to quantify the increased risk of oral contraceptive failure in epileptics.

By April 1976 there were 100 women in the RCGP study who had taken combined oral contraceptives for a total of 262 years after a diagnosis of epilepsy had been recorded. The medication prescribed for epileptics is not recorded in the RCGP study. Five pregnancies had occurred, made up of one apparent method failure and four patient failures. (There was doubt about one of the patient failures in that conception may have occurred with a progestogen-only preparation just before a change was made to a combined pill.)

My data from the whole study included 97 failures in approximately 48350 years, 10 of the failures being apparent method failures. The difference in failure rate from that of the epileptics was statistically significant at the $1^{\circ}{ }_{0}$ level for total failures, but not statistically significant for apparent method failures. Thus it seems that an epileptic taking a combined pill is not as well protected against pregnancy as most women using this method: however, the protection is likely to be as good as that offered by other reversible methods.

I should like to thank the staff of the RCGP oral contraceptive study, particularly Miss Jean Dufty, for their help and generosity in providing me with data.

ARTHUR JOHN

Shepshed,

Loughborough, Leics

Robertson, Y R, and Johnson, E S, Current Medical Research and Opinion, 1976, 39,647 . Hempel, E, et al, Zentralblatt für Gynäkologie, 1973, 95,1451

Janz, D, and Schmidt, D, Lancet, 1974, 1, 1113 ceptives and Health, London, Pitman Medical, 1974.

\section{Management of sexual dysfunction}

SIR,-We were interested to read the views of Drs C Q Mountjoy and T F Davies (17 July, $p$ 176) on the importance of adequate physical screening in cases presenting as disorders of sexual function. Indeed, we wholeheartedly agree that the effects of physical factors should not be underestimated, but we feel that emphasis should be placed on the notion of multifactorial causation, also referred to by your correspondents, because of the implications for diagnostic and therapeutic services. It is precisely this diversity of possible causal and/or contributory factors which necessitates thorough assessment of each case presenting; sophisticated screening for physical and endocrine abnormality should be matched by equally sophisticated assessment for psychological bases of the dysfunction.

One must then ask, however. how adequate screening can be ensured. Sexual problems may present in a variety of settings and the helping agents involved may be from a variety of disciplines. Within the health services gynaecologists, specialists in genitourinary medicine, endocrinologists, psychiatrists, clinical psychologists, and members of the primary health care team may be presented with complaints of sexual dysfunction in their patients. If one accepts the possibility of 